\title{
Identification of Rodent Species That Infest Poultry Houses in Mafikeng, North West Province, South Africa
}

\author{
Tsepo Ramatla $\mathbb{D}^{\mathrm{D}},{ }^{1}$ Nthabiseng Mphuthi, ${ }^{1}$ Kutswa Gofaone, ${ }^{1}$ Moeti O. Taioe, \\ Oriel M. M. Thekisoe, ${ }^{3}$ and Michelo Syakalima ${ }^{1}$ \\ ${ }^{1}$ Department of Animal Health, School of Agriculture, Faculty of Natural and Agricultural Science, Mafikeng Campus, \\ North West University, Private Bag X2046, Mmabatho, 2735, South Africa \\ ${ }^{2}$ Center for Conservation Science, National Zoological Gardens of South Africa, South African National Biodiversity Institute, \\ PO Box 754, Pretoria, 0001, South Africa \\ ${ }^{3}$ Unit for Environmental Sciences and Management, North West University, Potchefstroom Campus, Private Bag X6001, \\ Potchefstroom 2520, South Africa \\ Correspondence should be addressed to Tsepo Ramatla; ra21205450@gmail.com
}

Received 1 November 2018; Accepted 25 March 2019; Published 18 April 2019

Academic Editor: Hynek Burda

Copyright (C) 2019 Tsepo Ramatla et al. This is an open access article distributed under the Creative Commons Attribution License, which permits unrestricted use, distribution, and reproduction in any medium, provided the original work is properly cited.

\begin{abstract}
Rodents cause serious adverse effects on farm production due to destruction of food, contamination of feed, and circulation of diseases. The extent of damage or the diseases spread will depend on the type of rodents that invade the farm. This study was conducted in order to find out the species of rodents that infest poultry farms around Mafikeng, North West Province of South Africa. The study was part of a broader project that was investigating Salmonella vectors in the poultry farms around the province. The study trapped 154 rodents from selected farms and used the Cytochrome oxidase subunit 1 (COI) and the Cytochrome b (Cytb) barcoding genes for species identification. Two rodent pest species, namely, Rattus rattus (the black rat) and Rattus tanezumi (the Asian Rat/Asian House Rat) were identified. A total of 99 (64.3\%) were identified as Rattus rattus and 55 (35.7\%) were Rattus tanezumi. Between the two target genes, Cyt-b gene was only able to identify 40 (25.97\%) of the total samples while COI was more efficient and amplified all the samples and thus was a better target gene for this kind of identification. The two rat species identified are known vectors of serious diseases; thus their presence should be regarded as an indication of high risk for diseases. Despite having been detected in the country before, finding $R$. tanezumi as the second largest rat species in the area was unexpected since this species is known to be indigenous to Asia.
\end{abstract}

\section{Introduction}

Rodents are relatively small mammals belonging to the order Rodentia that includes porcupines, rats, mice, squirrels and marmots [1]. They are famously known to cause huge losses to stored food, crops, and property and also to transmit many pathogens that cause diseases of humans and animals [2]. The house mouse (Mus musculus), roof rats (Rattus rattus), and the brown rat ( $R$. norvegicus) are the three main species of rodents usually found worldwide [3]. The genus Rattus is one of the most common rodents found in poultry houses worldwide.

The genus Rattus consists mainly of Black rat (R. rattus), Norway rat ( $R$. norvegicus), Asian rat ( $R$. tanezumi), and $R$. mulium. The genus has some of the most adaptable rodents in the world and most of them have their origins in Asia where they migrated from to other parts of the world following the development of agriculture which provided food and shelter for their survival. Their intricate association with farms makes them very important vectors of pathogens some of which are zoonotic. For instance, the brown rat is famous as a carrier of gastrointestinal helminths and mites responsible for Plague, the black rat is a carrier of trematode species, cestode species, and Salmonella spp., and the Asian rat is a source of gastrointestinal helminths [4-7].

Identifying the rodent species in a farm set-up is, therefore, important in determining the specific rat species' risk to disease as well as other adverse effects in a farm. 


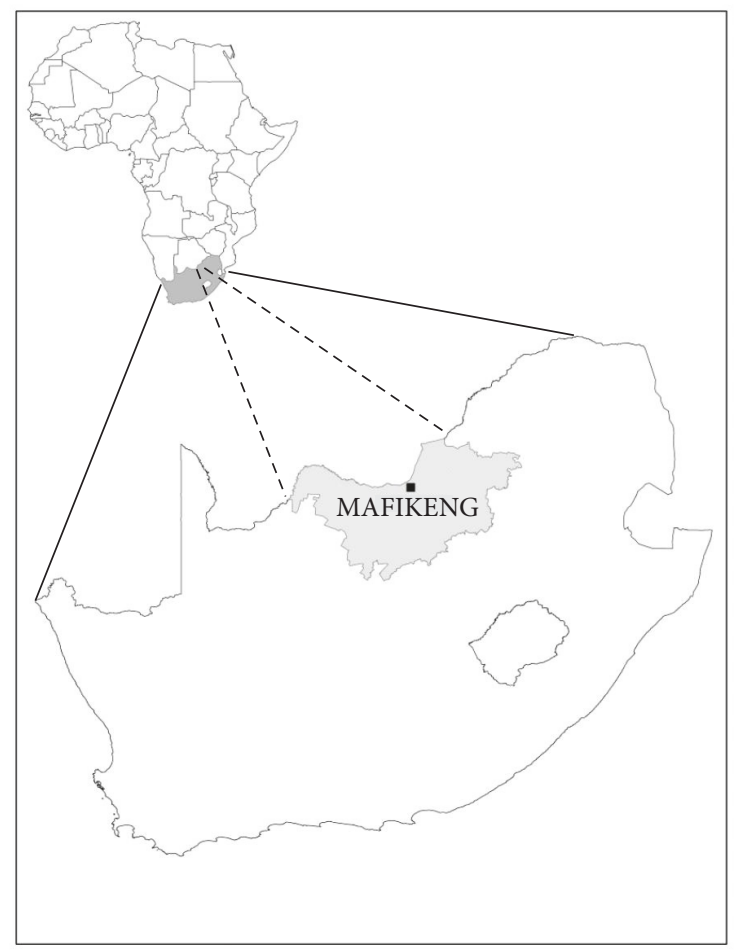

FIgURE 1: Map of Africa showing the Mafikeng sampling area in the North West Province of South Africa.

Unfortunately, rodents are not very easy to distinguish by the routine methods available that use physical attributes and so molecular identification has been offering the best option for identification. Molecular identification can be achieved by a number of methods but DNA barcoding, which is a taxonomic method that uses a short genetic marker in an organism's DNA to identify it to a particular species, has been found easy and particularly effective for this purpose [8]. The target gene used for barcoding is the COI gene which is a very common gene among species and has been fairly conserved over generations $[9,10]$. Another gene commonly used is the Cytochrome $b$ gene which is also a very good discriminatory gene for species identification $[8,11]$. These two genes were, therefore, used in this study to identify rodents in poultry houses from selected farms around Mafikeng, North West Province of South Africa.

\section{Materials and Methods}

2.1. Study Area. The study was carried out in Mafikeng, the North West Province of South Africa. The North West Province is referred to as one of the biggest agricultural production areas in South Africa, with some of the largest cattle herds in the country found at Stellaland (Vryburg) and mixed crop farming land. The province is also the second largest chicken producer in South Africa at $21.3 \%$ after Western Cape with 21.9\% (SAPA, 2014). The province has four districts, namely, Bojanala Platinum, Ngaka Modiri Molema, Dr Ruth Segomotsi Mompati, and Dr Kenneth Kaunda. This study was conducted around Mafikeng in The Ngaka Modiri
Molema district (Figure 1). The city lies between 25 and $28^{\circ} \mathrm{C}$ South of the Equator and 22 and $28^{\circ} \mathrm{C}$ longitude east of the Greenwich meridian. It shares an international border with the Republic of Botswana in the North and is $260 \mathrm{~km}$ West of Johannesburg. Mafikeng is built on the open veld at an elevation of $1500 \mathrm{~m}$ along the banks of the Upper Molopo River. Climatic conditions of the province differ significantly from West to East. The Western region receives less than $300 \mathrm{~mm}$ of rain per annum, the central region around $550 \mathrm{~mm}$ per annum, while the Eastern and South Eastern regions receive over $600 \mathrm{~mm}$ per annum [12].

2.2. Collection of Samples. A list of poultry farms in the Mafikeng area was compiled using the Department of Agriculture records. A few farms in the north, south, east, and west were randomly selected, the farmers were approached, and those that agreed were included in the study. Rodents were captured using Sherman rat traps [13] baited with peanut butter plus cheese and placed where the rats regularly visit. The traps were checked each morning during three consecutive days. The target number of rats was between 150 and 200 based on previous studies [2, 5]. Live rats were euthanized humanely using chloroform inhalation [14]. Their surface was disinfected with $70 \%$ ethyl alcohol before dissection. Dissection of the abdominal cavity was done using a surgical blade, a pair of forceps, and kidneys were harvested and placed in $4^{\circ} \mathrm{C}$ until processing. Extra care was taken in order to avoid cross-contamination by using new disposable utensils like scalpels, forceps, petri-dishes, and gloves for each sample. After collecting the samples, carcasses were 
placed in carcass containers located within designated carcass refrigerators/freezers in the post mortem room and then incinerated.

2.3. DNA Extraction. DNA was extracted from tissues (kidney) using a QIAamp DNA Blood and Tissue Kit [Qiagen, Hilden, Germany (No. 69504)]. The procedure was performed according to protocols provided by the manufacturers. The DNA extracted was stored at $-80^{\circ} \mathrm{C}$ until analysis by PCR.

2.4. Evaluation of the Quantity and Quality of Isolated DNA. The amount of DNA extracted from the samples was determined by spectrophotometry with a NanoDrop ND-1000 system (NanoDrop Technologies, Inc., Wilmington, DE, USA). The purity of DNA was determined spectrophotometrically from the ratio of absorbance at 260 and $280 \mathrm{~nm}\left(\mathrm{~A}_{260} / \mathrm{A}_{280}\right)$. A ratio of between 1.7 and 2 indicates an excellent quality of DNA.

\subsection{PCR for Amplification of CO1 and Cyt-b Genes of Captured} Rats. For rat species identification, PCR was used targeting the $C O 1$ and $C y t-b$ genes of the rats following published protocols $[8,15]$. The final reaction mixture was $25 \mu \mathrm{l}$ and consisted of $2 \mu \mathrm{l}$ of template DNA, $8.5 \mu \mathrm{l}$ double distilled water, 2X Dream Taq Green PCR Master Mix (2X Dream Taq Green buffer, $4 \mathrm{mM} \mathrm{MgCl}_{2}, 0.4 \mathrm{mM}$ ) of each dNTP and $1 \mathrm{unit} / \mu \mathrm{l}$ of thermo stable Taq polymerase (Thermo Scientific, USA), the primer mix contained $10 \mu \mathrm{M}$ of each oligonucleotide primer.

To amplify the $750 \mathrm{bp}$ product of COI, the primers used were BatL5310 (5' -CCT ACT CRG CCA TTT TAC CTA TG$\left.3^{\prime}\right)$ and R6036R ( $5^{\prime}$-ACT TCT GGG TGT CCA AAG AAT CA $\left.-3^{\prime}\right)$. The PCR conditions were one initial denaturation step of $94^{\circ} \mathrm{C}$ for $2 \mathrm{~min}$, subjected to 35 cycles, denaturation at $94^{\circ} \mathrm{C}$ for $30 \mathrm{sec}$, annealing at $60^{\circ} \mathrm{C}$ for $30 \mathrm{sec}$, and the first extension at $72^{\circ} \mathrm{C}$ for $1 \mathrm{~min}$ and a final extension step of $72^{\circ} \mathrm{C}$ for $5 \mathrm{~min}$ with the holding temperature at $4^{\circ} \mathrm{C}$ [15].

To amplify the $762 \mathrm{bp}$ product of $C y t-b$ gene, the primers used were RGu2L (CAG CAT TTA ACT GTG ACT AAT GAC) and RCb9H (TAC ACC TAG GAG GTC TTT AAT TG), with the following PCR conditions used: $94^{\circ} \mathrm{C}$ for $3 \mathrm{~min}$, $35 \mathrm{cycles}$ of $94^{\circ} \mathrm{C}$ for $30 \mathrm{sec}, 60^{\circ} \mathrm{C}$ for $30 \mathrm{sec}, 72^{\circ} \mathrm{C}$ for $1 \mathrm{~min}$, followed by a final extension at $72^{\circ} \mathrm{C}$ for $5 \mathrm{~min}$, and cooling down to $4^{\circ} \mathrm{C}$ and storage [16].

The PCR amplicons in both PCR reactions were analysed by electrophoresis in $1 \%(\mathrm{w} / \mathrm{v})$ agarose gel containing ethidium bromide $\left(10 \mu \mathrm{g} \mathrm{ml}^{-1}\right)$ then viewed under UV light at $420 \mathrm{~nm}$ wavelength. A ChemiDoc Imaging System (Bio-Rad ChemiDocTM MP Imaging System, UK) was used to capture the image using Gene Snap (version 6.00.22) software.

2.6. Sequencing. Seventeen micro liters of all positive PCR products were sent for sequencing at Inqaba Biotechnical Industries (Pty) Ltd in Pretoria, South Africa. The acquired sequence was aligned against GenBank data base using Basic Local Alignment Search Tool (BLAST) (www.ncbi.nlm.nih.gov/BLAST) from the National Center for Biotechnology Information (NCBI) to identify sequences with high similarity (38). One direction sequencing was done.

2.7. Phylogenetic Analysis. Gene sequences obtained from all positively tested amplicons were edited using BioEdit [17] to remove any degenerate base pairs and then saved as FASTA format. To confirm sequences obtained from CO1 and Cyt$b$ analysis, the nucleotide basic local alignment search tool (BLASTn) was used. Only gene sequences with $97 \%$ to $100 \%$ similarity match score were considered as significant.

The phylogenetic tree was constructed to illustrate the evolutionary relationships among Rattus spp. Multiple alignments of the sequences were carried out by MAFFT program 6.864 against corresponding nucleotide sequences retrieved from Gen-Bank. Evolutionary distance matrices were generated [18]. The aligned $C y t-b$ sequences were used to construct a phylogenetic tree as implemented in the MEGA 7 package and the neighbor-joining (NJ) and distance matrix methods were used [18]. A bootstrap confidence analysis was performed with 1000 replicates. A putative chimeric sequence was identified using the Chimera Buster 1.0 software. Manipulation and tree editing was carried out using Tree View [17].

For $\mathrm{CO} 1$ analysis, multiple and pairwise alignments were done by ClustalW on Mega 7 [19]. Subsequently, the evolutionary history was inferred based on the Hasegawa-KishinoYano model [20] with 1000 bootstrap support values. The percentage of trees in which the associated taxa clustered together is shown next to the branches. Initial trees for the heuristic search were obtained automatically by applying Neighbor-Join and BioNJ algorithms to a matrix of pairwise distances estimated using the Maximum Composite Likelihood (MCL) approach and then selecting the topology with superior log likelihood value. The rate variation model allowed for some sites to be evolutionarily invariable $([+\mathrm{I}]$, $69.02 \%$ sites). The tree is drawn to scale, with branch lengths measured in the number of substitutions per site.

Ethics Committee Approval. Prior to the commencement of the study, the research proposal was approved based on Animal Research Ethics Committee (NWU-00274-18A5) guidelines by North West University Research Ethics Regulatory Committee (NWU-RERC).

\section{Results}

3.1. Rodent's Identification. A total of 154 rat samples were captured and examined using $C y t-b$ and $C O I$ genes to identify the rodent species. Of the 154 rodents, 99 (64.3\%) were identified by the COI gene primers as Rattus rattus and the rest 55 (35.7\%) were Rattus tanezumi (Table 1). Figure 2 shows how the fragments appeared on a gel after amplification with of the COI gene primers.

Using the Cyt-b gene primer only 40 samples were amplified from a total of 154 as follows: Rattus rattus 26 (16.9\%) and Rattus tanezumi 14 (9.1\%) (Table 1). Many samples did not show any amplification products for $C y t-b$ as shown in Figure 3. For the samples which were not amplified, the PCR was unsuccessful in three repetitions. 
TABLE 1: Number of rodents from different farms that were identified using both CO1 and Cyt-b gene.

\begin{tabular}{|c|c|c|c|c|}
\hline Farm & No. of rats & Species & Cytochrome oxidase 1 & Cytochrome b \\
\hline \multirow{2}{*}{ A } & \multirow{2}{*}{25} & (i) Rattus rattus & 19 & 14 \\
\hline & & (ii) Rattus tanezumi & 6 & 2 \\
\hline \multirow{2}{*}{ B } & \multirow{2}{*}{3} & (i) Rattus rattus & 3 & - \\
\hline & & (ii) Rattus tanezumi & - & - \\
\hline \multirow{2}{*}{$\mathrm{C}$} & \multirow{2}{*}{21} & (i) Rattus rattus & 15 & 4 \\
\hline & & (ii) Rattus tanezumi & 6 & - \\
\hline \multirow{2}{*}{$\mathrm{D}$} & \multirow{2}{*}{17} & (i) Rattus rattus & 10 & 1 \\
\hline & & (ii) Rattus tanezumi & 7 & 2 \\
\hline \multirow{2}{*}{$\mathrm{E}$} & \multirow{2}{*}{68} & (i) Rattus rattus & 46 & 10 \\
\hline & & (ii) Rattus tanezumi & 22 & 5 \\
\hline \multirow{2}{*}{$\mathrm{H}$} & \multirow{2}{*}{20} & (i) Rattus tanezumi & 14 & 1 \\
\hline & & (ii) Rattus rattus & 6 & 1 \\
\hline Total & 154 & & 154 & 40 \\
\hline
\end{tabular}

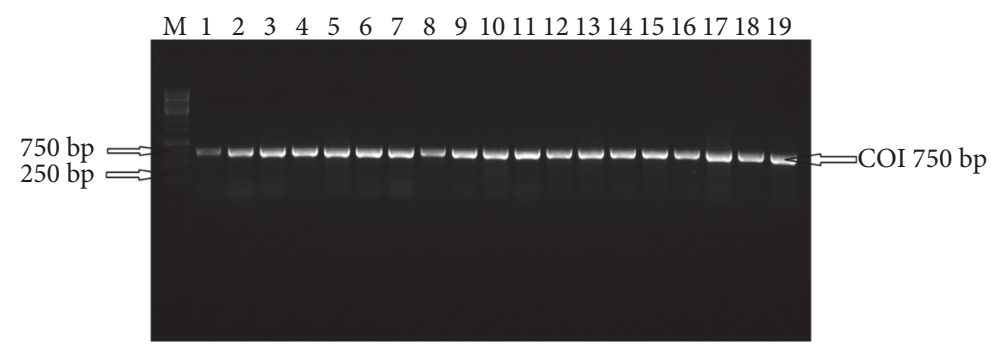

FIGURE 2: PCR amplification of COI gene. Lane M: molecular weight marker (1kb). Lanes 1-19 are COI gene fragments from DNA extracted from Rodents.

3.2. Phylogeny of R. rattus and R. tanezumi. Phylogeny of $R$. rattus and $R$. tanezumi for both Cytochrome Oxidase I (COI) and Cytochrome b (Cyt-b) genes was inferred using sequences derived from this study as well as those downloaded from GenBank from different countries around the world. In both tree topologies monophyly between $R$. rattus and $R$. tanezumi was well supported with high bootstrap support values. Figure 4 represents the tree topology inferred for $C y t-b$ gene. Hylomyscus simus was used as an out-group and three major clades were derived from the analysis. The clades consisted of the Rattus rattus clade, $R$. tanezumi clade, and $R$. norvegicus clade, respectively. All three derived clades had well supported bootstrap values.

For the COI tree topology, Hylomyscus simus and Micromy enthrotis were used as out-groups (Figure 5). In this phylogenetic tree, a monophyletic clade between $R$. rattus and $R$. tanezumi was again supported with high bootstrap support values. The observations made from the two phylogenetic trees do confirm that the samples collected in this study are indeed $R$. rattus and $R$. tanezumi, respectively.

3.3. Accession Numbers Obtained from GenBank. The representative sequences obtained in this study have been deposited to the GenBank database with assigned accession numbers ranging from MK645246 to MK645295.

\section{Discussion}

The primary objective of the study was to document rodent species that invade poultry houses in the North-West Province in particular and in South Africa in general. This information is important for economic as well as disease risk assessment $[21,22]$. We were therefore able to show that of the 154 rodents, $99(64.3 \%)$ were $R$. rattus and the other 55 (35.7\%) were $R$. tanezumi. The $R$. rattus (the Black rat) was the most dominant species and it has been known to be in South Africa for many years $[23,24]$. It is an important rat species because it is the most damaging invasive rodent in the world [1]. Furthermore, the rat has also been known as a vector of diseases infectious to humans [24]. The rat is a carrier of trematode species, cestode species, and nematode species [5]. A study by Reusken et al. [4] also implicated these rats as vectors spreading Coxiella burnetii. It may also carry important protozoa which are mainly dangerous for immune compromised patients [1]. Bacterial pathogens like Salmonella that are important to both humans and livestock have also been isolated from $R$. rattus in many countries, i.e., Japan, [25], Reunion Island [26], Pakistan [27], and Canada [14]. In the phylogenetic tree it clustered well with the species found in India, Jordan, Tanzania, and other South African studies. The rat's occurrence, especially in livestock farms, is therefore a significant health risk factor. 


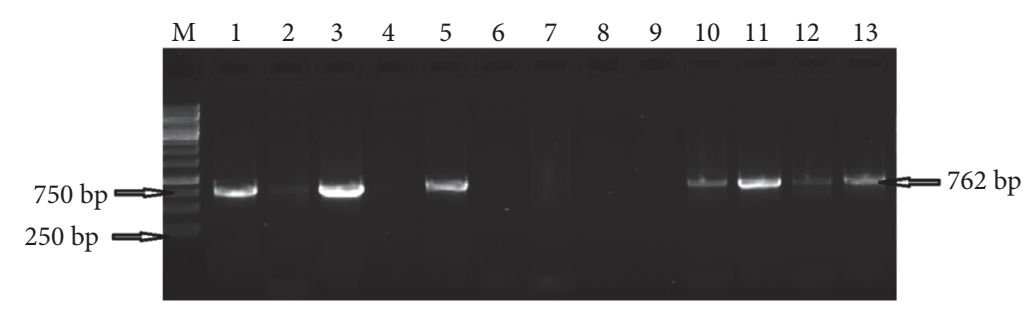

FigurE 3: Lane M: molecular weight marker (1kb). Lanes 1, 2, 3, 5, 10, 11, 12, 13: amplified genes for Cyt-b. Lanes 4, 6, 7, 8, 9 are samples that were not amplified.

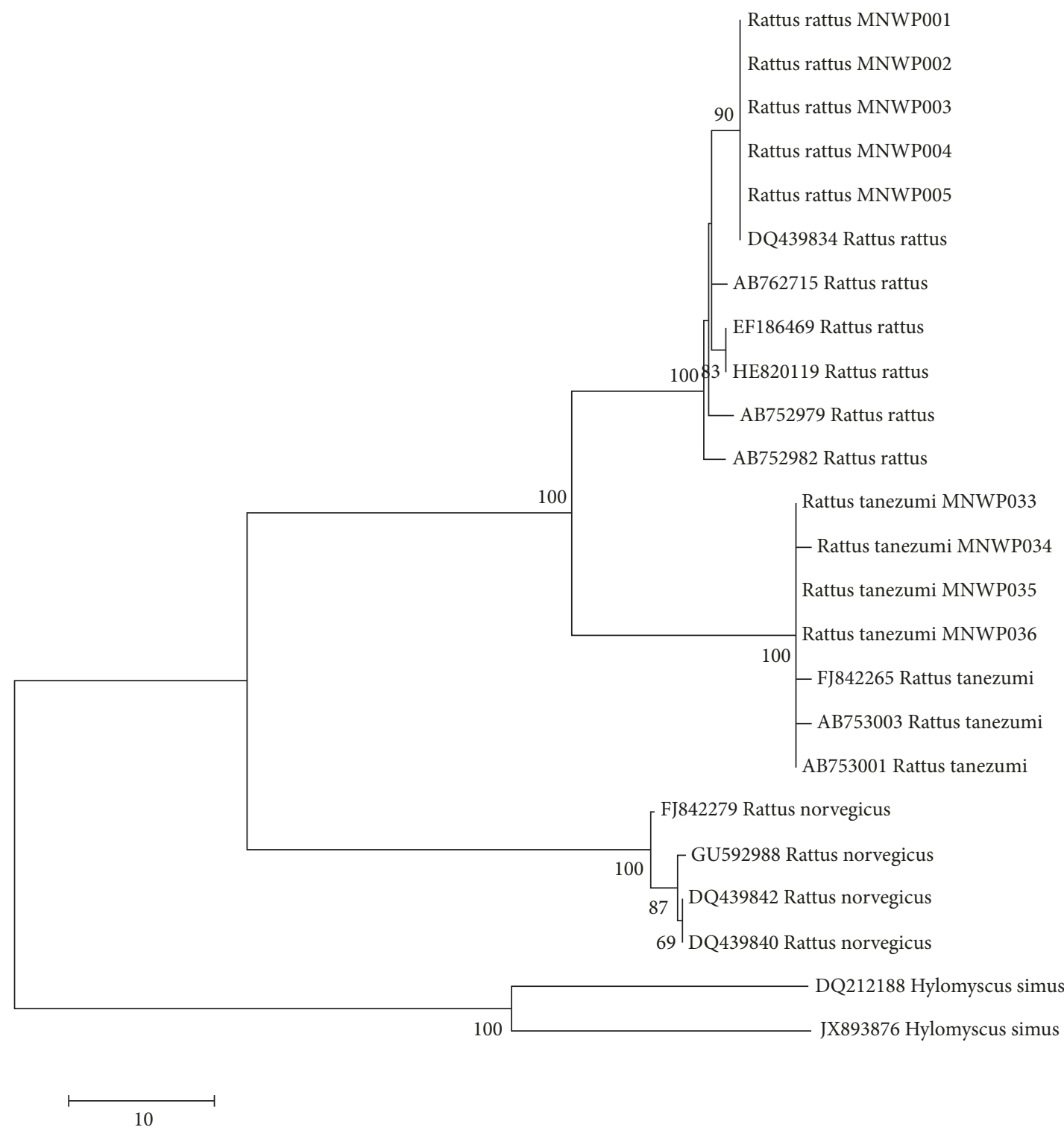

FIGURE 4: Neighbour-joining tree from the Cyt-b gene. The analysis involved 24 nucleotide sequences whereby 9 sequences were derived from this study and the remaining from the NCBI database with 1000 replicates. All positions containing gaps and missing data were eliminated. There were a total of 608 positions in the final dataset. 


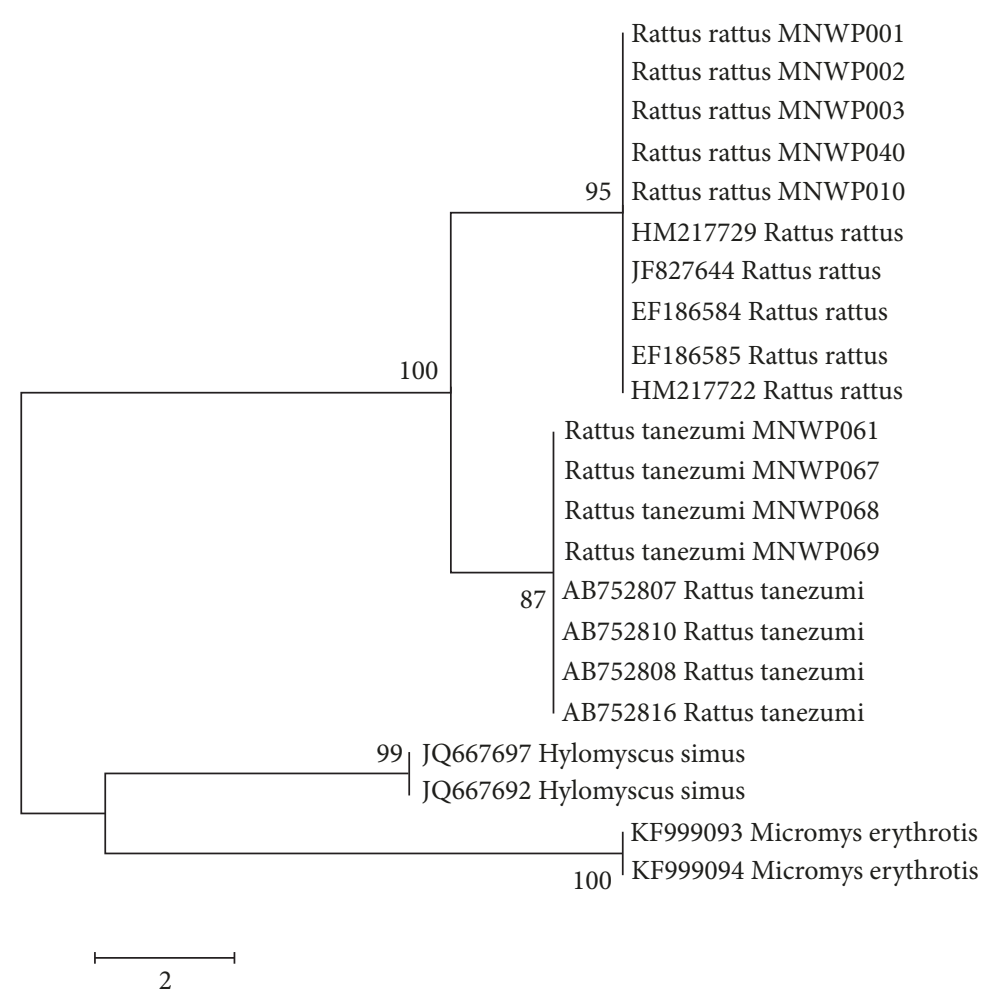

FIGURE 5: Phylogenetic tree based on distance matrix analysis of COI gene sequences from $R$. rattus and $R$. tanezumi based on the HasegawaKishino-Yano model with 1,000 bootstrap support values. The analysis involved 22 nucleotide sequences whereby 9 sequences were derived from this study and the remaining from the NCBI database. All positions containing gaps and missing data were eliminated. There were a total of 598 positions in the final dataset.

The other Rattus species found in this study, R. tanezumi, has also been detected in South Africa before [6, 28]. $R$. tanezumi was first identified in Limpopo Province [24]; however to the best of our knowledge, this is the first report of its detection in the North West Province of South Africa. What is also significant was the finding that it is the second most dominant species in the poultry farms meaning it is getting more prolific and invasive all over the country. This rat species is predominantly found in Asia and wherever it is discovered it will always have its origins from Asia hence the name the Asian House rat. It is a carrier of hantaviruses [29] and it has also been found to carry important mites as well as helminths [6,7]. Apart from diseases, the rat plays an important role by causing serious damage to field crops, destroying food stores, and also causing infrastructural damage $[21,30,31]$. It is obvious, therefore, that its increasing presence in South Africa brings with it these negative traits in the farm and human environment.

Of the two mitochondrial DNA genes used for this study, $c y t-b$ and COI, the Cyt-b could only amplify $40(25.97 \%)$ samples out of 154 . However, COI gene amplified all the samples thus demonstrating that $C O I$ is a better gene for this purpose. The effectiveness of COI gene in species classification has also been reported before in wildlife [9], nematodes [32], reedbuck [10], birds [33], rodents [15], and lepidoptera [34]. The COI genes have been the most frequent methods used for species identification in animal biological studies due to its high degree of phylogenetic species differentiation as compared to other mtDNA genes [33]. Our study confirmed these findings and recommends its superior usage over $C y t-b$.

\section{Conclusion}

The study established that the two rodent species found in poultry houses around Mafikeng, North West province of South Africa were $R$. tanezumi and $R$. rattus. The finding that $R$. tanezumi is the second most prominent rat species in these farms was unexpected because the rat species was first reported in South Africa not so long ago and that the species is not indigenous to Africa but Asia. It is thus important to expect it to increase and become a prominent species in the years to come. The study also confirmed that cytochrome oxidase I (COI) genes serve as a reliable and more precise target for identification of these rodent species.

\section{Data Availability}

The sequences data used to support the findings of this study are available from the corresponding author upon request.

\section{Conflicts of Interest}

The authors declare no conflicts of interest. 


\section{Acknowledgments}

This work was supported by the funds made available by NWU Post-Graduate Bursary, Faculty of Natural and Agricultural Sciences and the Department of Animal Health, North-West University Mafikeng Campus.

\section{References}

[1] B. G. Meerburg, G. R. Singleton, and A. Kijlstra, "Rodent-borne diseases and their risks for public health," Critical Reviews in Microbiology, vol. 35, no. 3, pp. 221-270, 2009.

[2] A. Wakawa, F. Mohammed, and H. Mamman, "Isolation and antibiotic susceptibility of escherichia coli and salmonella gallinarum isolated from rats in commercial poultry farms with recurrent colibacillosis and fowl Typhoid Cases in Zaria, Nigeria," Journal of Veterinary Advances, vol. 5, no. 11, pp. 1147$1152,2015$.

[3] A. Backhans and C. Fellström, "Rodents on pig and chicken farms-a potential threat to human and animal health," Infection Ecology \& Epidemiology, vol. 2, no. 1, p. 17093, 2012.

[4] C. Reusken, R. van der Plaats, M. Opsteegh, A. de Bruin, and A. Swart, "Coxiella burnetii (Q fever) in Rattus norvegicus and Rattus rattus at livestock farms and urban locations in the Netherlands; could Rattus spp. represent reservoirs for (re)introduction?" Preventive Veterinary Medicine, vol. 101, no. 1-2, pp. 124-130, 2011.

[5] F. Franssen, P. Siribat, A. Ribas, and S. Morand, "Helminth parasites in black rats (Rattus rattus) and brown rats (Rattus norvegicus) from different environments in the Netherlands," Infection Ecology \& Epidemiology, vol. 6, no. 1, p. 31413, 2016.

[6] K. Chaisiri, W. Chaeychomsri, J. Siruntawineti, A. Ribas, V. Herbreteau, and S. Morand, "Diversity of gastrointestinal helminths among murid rodents from northern and northeastern Thailand," Southeast Asian Journal of Tropical Medicine and Public Health, vol. 43, no. 1, pp. 21-28, 2012.

[7] K. Chaisiri, P. Siribat, A. Ribas, and S. Morand, "Potentially zoonotic helminthiases of murid rodents from the indo-chinese peninsula: Impact of habitat and the risk of human infection," Vector-Borne and Zoonotic Diseases, vol. 15, no. 1, pp. 73-85, 2015.

[8] K. M. West, Investigating patterns of prehistoric dispersal in Eastern Polynesia: a commensal approach using complete ancient and modern mitochondrial genomes of the Pacific rat, Rattus exulans, Thesis University of Otago, 2016.

[9] M. Syakalima, M. Munyeme, and J. Yasuda, "Cytochrome C oxidase sequences of zambian wildlife helps to identify species of origin of meat," International Journal of Zoology, vol. 2016, Article ID 1808912, 6 pages, 2016.

[10] D. L. Dalton and A. Kotze, "DNA barcoding as a tool for species identification in three forensic wildlife cases in South Africa," Forensic Science International, vol. 207, no. 1-3, pp. e51-e54, 2011.

[11] A. E. Balakirev and V. V. Rozhnov, "Phylogenic relationships and species composition in the genus Niviventer (Rodentia, Muridae) based on studies of the cytochrome $b$ gene of mtDNA," Moscow University Biological Sciences Bulletin, vol. 65, no. 4, pp. 170-173, 2010.

[12] T. Ramatla, L. Ngoma, M. Adetunji, and M. Mwanza, "Evaluation of antibiotic residues in raw meat using different analytical methods," Antibiotics, vol. 6, no. 4, p. 34, 2017.

[13] L. Dizney, P. D. Jones, and L. A. Ruedas, "Efficacy of three types of live traps used for surveying small mammals in the pacific northwest," Northwestern Naturalist, vol. 89, no. 3, pp. 171-180, 2008.

[14] C. G. Himsworth, E. Zabek, A. Desruisseau et al., "Prevalence and characteristics of escherichia coli and salmonella spp. In the feces of wild Urban Norway and black rats (rattus norvegicus and rattus rattus) from an inner-city neighborhood of Vancouver, Canada," Journal of Wildlife Diseases, vol. 51, no. 3, pp. 589-600, 2015.

[15] R. R. Lakshminarayanan, A. Shanmugam, and A. Govindaraju, "Sequencing of COI gene in four rodent pests for species identification," DNA Barcodes, vol. 3, no. 1, 2015.

[16] J. H. Robins, P. A. McLenachan, M. J. Phillips, B. J. McComish, E. Matisoo-Smith, and H. A. Ross, "Evolutionary relationships and divergence times among the native rats of Australia," BMC Evolutionary Biology, vol. 10, no. 1, article no. 375, 2010.

[17] J. Moyane, A. Jideani, and O. Aiyegoro, "Antibiotics usage in food-producing animals in South Africa and impact on human: Antibiotic resistance," African Journal of Microbiology Research, vol. 7, no. 24, pp. 2990-2997, 2013.

[18] H. Hendrickson, E. S. Slechta, U. Bergthorsson, D. I. Andersson, and J. R. Roth, "Amplification-mutagenesis: evidence that "directed" adaptive mutation and general hypermutability result from growth with a selected gene amplification," Proceedings of the National Acadamy of Sciences of the United States of America, vol. 99, no. 4, pp. 2164-2169, 2002.

[19] S. Kumar, G. Stecher, and K. Tamura, "MEGA7: "Molecular evolutionary genetics analysis version 7.0 for bigger datasets," Molecular Biology and Evolution, vol. 33, no. 7, pp. 1870-1874, 2016.

[20] M. Hasegawa, H. Kishino, and T. Yano, "Dating of the humanape splitting by a molecular clock of mitochondrial DNA," Journal of Molecular Evolution, vol. 22, no. 2, pp. 160-174, 1985.

[21] A. M. Stuart, G. R. Singleton, and C. V. Prescott, "Population ecology of the Asian house rat (Rattus tanezumi) in complex lowland agroecosystems in the Philippines," Wildlife Research, vol. 42, no. 2, pp. 165-175, 2015.

[22] M. T. Mengak, Rats and Mice: Get Them Out of Your House and Yard, 2009, https://athenaeum.libs.uga.edu/bitstream/handle/ 10724/12234/C970.pdf.

[23] A. D. Bastos, D. Nair, P. J. Taylor et al., "Genetic monitoring detects an overlooked cryptic species and reveals the diversity and distribution of three invasive Rattus congeners in south Africa," BMC Genetics, vol. 12, no. 1, p. 26, 2011.

[24] A. Bastos, C. Chimimba, E. Von Maltitz, F. Kirsten, and S. Belmain, "Identification of rodent species that play a role in disease transmission to humans in South Africa," in Proceedings of the South African Society for Veterinary Epidemiology and Preventive Medicine, pp. 78-83, 2005.

[25] D. V. Umali, R. R. S. P. Lapuz, T. Suzuki, K. Shirota, and H. Katoh, "Transmission and shedding patterns of Salmonella in naturally infected captive wild roof rats (rattus rattus) from a Salmonella-contaminated layer farm," Avian Diseases, vol. 56, no. 2, pp. 288-294, 2012.

[26] C. Tessier, L. Parama Atiana, E. Lagadec, G. Le Minter, M. Denis, and E. Cardinale, "Wild fauna as a carrier of Salmonella in Reunion Island: Impact on pig farms," Acta Tropica, vol. 158, pp. 6-12, 2016.

[27] M. Mushtaq-ul-Hassan, I. Hussain, B. Shehzadi, M. Shaheen et al., "Occurrence of some zoonotic microorganisms in faecal matter of house rat (Rattus rattus) and house mouse (Musmusculus) trapped from various structures," Pakistan Veterinary Journal, vol. 28, no. 4, pp. 171-174, 2008. 
[28] R. W. Miller, Rattus tanezumi in the upland rice terraces of Banaue, Philippines: Demography, habitat use, crop damage and yield assessment, The University of New South Wales, Sydney, 2007.

[29] P. T. Iliev, G. Z. Georgiev, Z. T. Kirkova, and B. G. Chakarova, “A survey of helminth infections in the black rat from Stara Zagora district, Bulgaria," Macedonian Veterinary Review, vol. 40, no. 2, pp. 177-182, 2017.

[30] G. R. Singleton, S. Belmain, P. R. Brown, K. Aplin, and N. M. Htwe, "Impacts of rodent outbreaks on food security in Asia," Wildlife Research, vol. 37, no. 5, pp. 355-359, 2010.

[31] A. Al-Gendy, S. Baghdadi, S. S. Malek, and E. Dongol, "Incidence and damage assessment of rats (Mammalia: Rodentia) infesting poultry and animal farms and their stores in Upper Egypt," Journal of Phytopathology and Pest Management, vol. 4, no. 1, pp. 69-77, 2017.

[32] R. Callejón, M. De Rojas, C. Ariza, J. M. Ubeda, D. C. Guevara, and C. Cutillas, "Cytochrome oxidase subunit 1 and mitochondrial 16S rDNA sequences of Trichuris skrjabini (Tricocephalida: Trichuridae)," Parasitology Research, vol. 104, no. 3, pp. 715-716, 2009.

[33] P. D. N. Hebert, M. Y. Stoeckle, T. S. Zemlak, and C. M. Francis, "Identification of birds through DNA barcodes," PLoS Biology, vol. 2, no. 10, p. e312, 2004.

[34] M. Hajibabaei, D. H. Janzen, J. M. Burns, W. Hallwachs, and P. D. N. Hebert, "DNA barcodes distinguish species of tropical Lepidoptera," Proceedings of the National Acadamy of Sciences of the United States of America, vol. 103, no. 4, pp. 968-971, 2006. 


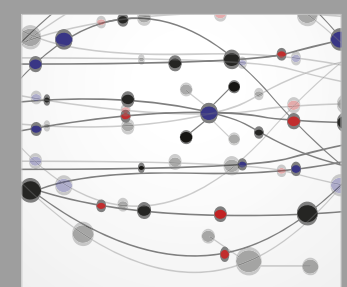

The Scientific World Journal
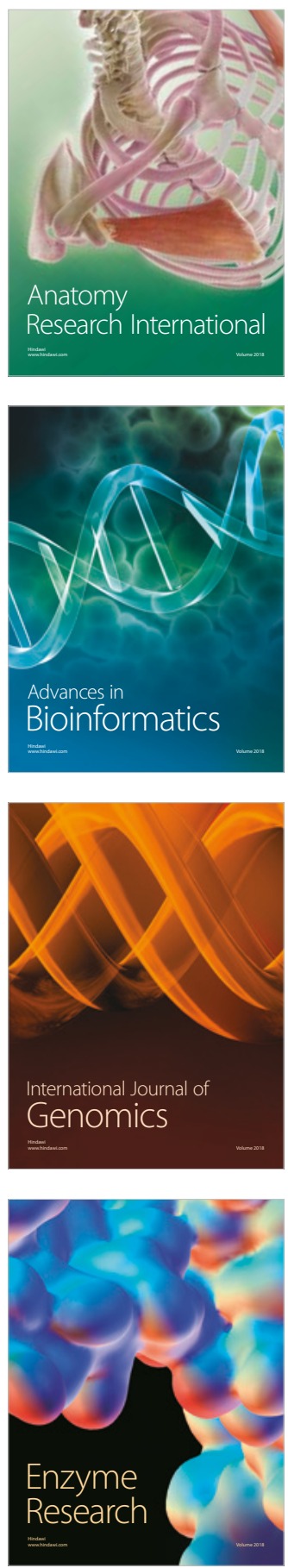
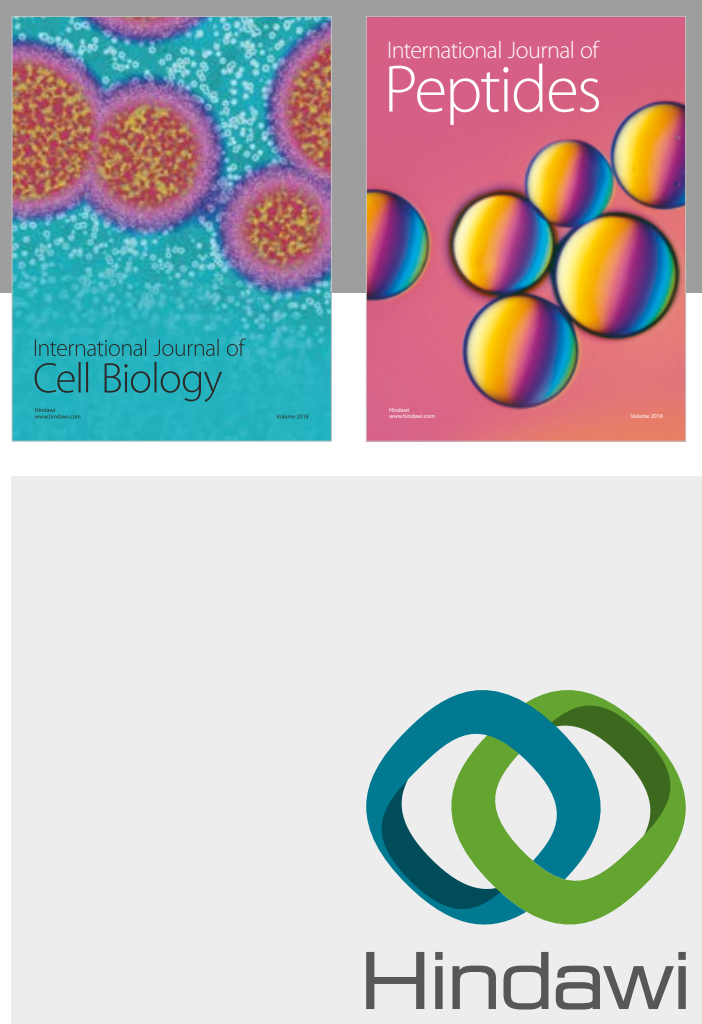

Submit your manuscripts at

www.hindawi.com
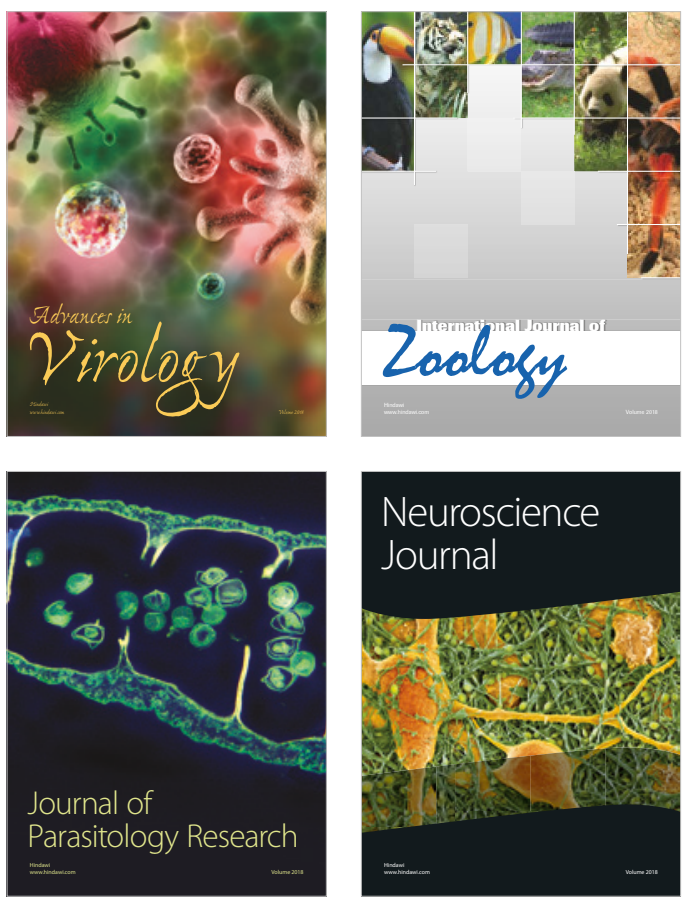
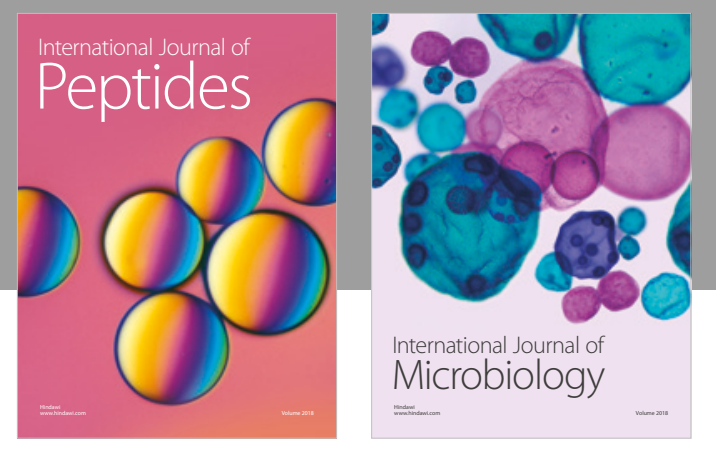

nternational Journal of Microbiology
Journal of
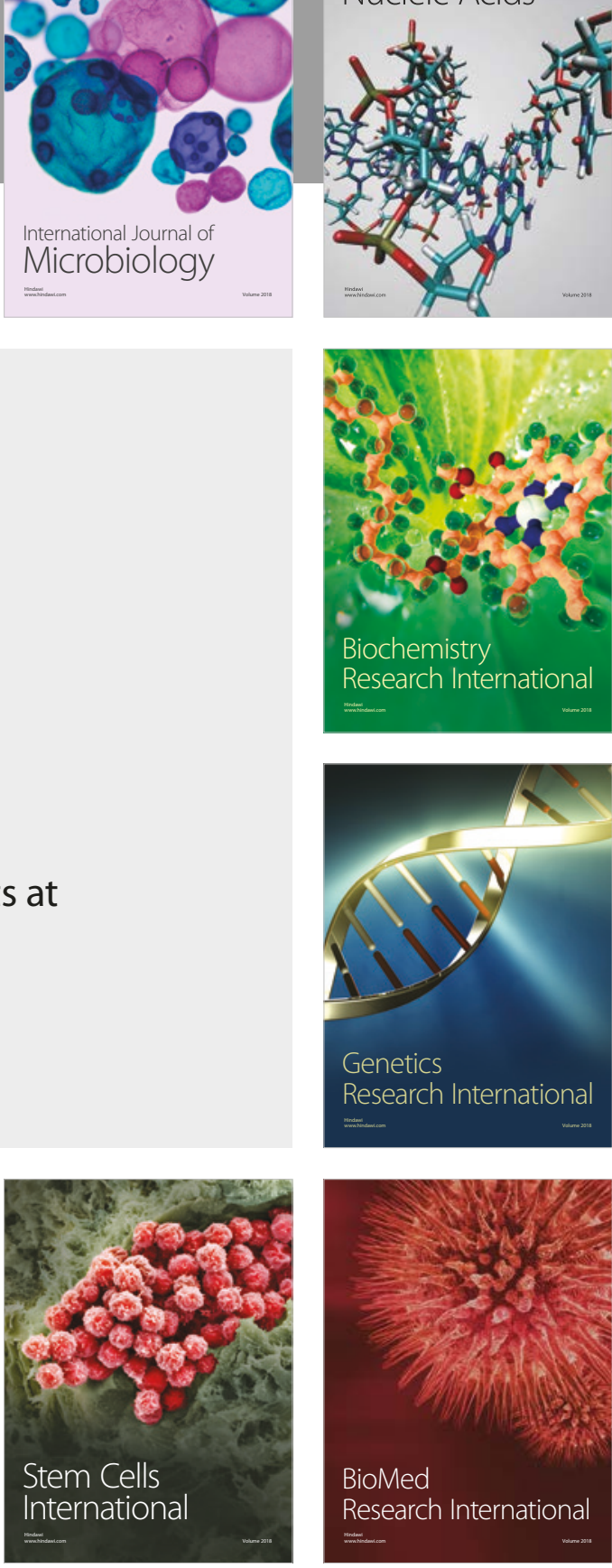
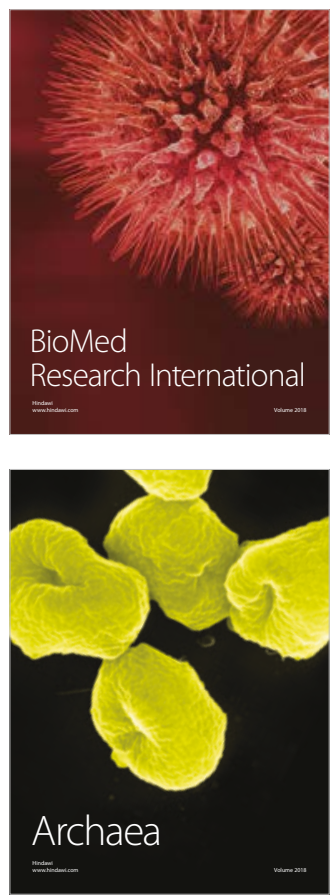